\title{
Asfixia postural o asfixia posicional por suspensión abdominal: ¿un diagnóstico de exclusión?.
}

\author{
Postural asphyxia or positional asphyxia caused by \\ abdominal suspension: a diagnostic reached by exclusion?.
}

\author{
M.A. Carnicero Giménez de Azcarate y cols. \\ Cuad Med Forense 2001;26:41-50
}

\begin{abstract}
Se trata del cadáver de un hombre de 83 años con antecedentes de accidentes cerebrovasculares de repetición, hipertensión arterial y diabetes mellitus tipo II, demencia senil con cuadros delirantes, hiperuricemia y prostatectomía. Vive en un centro de crónicos necesitando la ayuda de terceras personas para todas las actividades de la vida diaria. La cama donde se encuentra habitualmente tiene como medidas de seguridad una correa que se abrocha a la altura del abdomen y barras de seguridad a ambos lados. El mecanismo de apertura de las barras de seguridad se encuentra cerca de los pies y a ambos lados de la cama (algunos internos llegan a accionarlo con los pies). El interno fue hallado colgado de la correa de seguridad por la zona abdominal sobre el lateral izquierdo de la cama y con la cabeza y tórax situados en un plano inferior al resto del cuerpo. La barra de seguridad estaba bajada aunque su funcionamiento era correcto.

En la autopsia destacaban en el examen externo: surco de 3,5 cm de anchura, apergaminado en algunos tramos, situados en ambos hipocondrios y que cruza toda la cara anterior del tronco (Figura $n^{\circ}$ I). En el plano dorsal el surco es evidente pero menos marcado (Figura $n^{\circ} 2$ ). En la cabeza y la cara (Figura $n^{\circ} 3$ ) así como en la cara anterior del cuello y el hombro derecho se evidenció la presencia de piqueteado equimótico. Hiperemia conjuntival bilateral. En el examen interno destacaba congestión de las cubiertas meníngeas, atrofia cerebral, arteriosclerosis de la arteria basilar y vertebral izquierda; hidrotórax bilateral con colapso pulmonar derecho; pulmones de $400 \mathrm{~g}$ el derecho y $52 \mathrm{l} \mathrm{g}$ el izquierdo, congestivos y con material alimenticio ocupando las vías aéreas; el corazón pesó 397 g, presentaba arteriosclerosis coronaria calcificada y lesiones cicatriciales en la pared posterior del ventrículo izquierdo. El resto del examen interno únicamente reveló la existencia de congestión visceral generalizada. El análisis toxicológico no demostró la presencia de tóxicos. El examen histopatológico arrojó los siguientes resultados: Encéfalo: arteriosclerosis con placas de ateroma calcificadas que determinan estenosis del $25-45 \%$ en la arteria basilar y $60 \%$ en la vertebral izquierda, infarto antiguo en mesencéfalo y otras alteraciones de carácter senil .Los pulmones presentaban congestión, atelectasia del pulmón derecho, predominio de enfisema y edema en el pulmón izquierdo, así como la presencia de alimento que ocupa luces bronquiales y bronquiolares (Figura $n^{\circ} 4$ ), sobre todo en lóbulos izquierdos. El corazón presentaba ateromatosis coronaria con estenosis focal del $75 \%$ en las arterias coronarias descendentes anterior y posterior (Figura $n^{\circ} 5$ ), amiloidosis de ramas intramurales y cicatrices parcheadas en el tabique y ventrículo izquierdo.
\end{abstract}



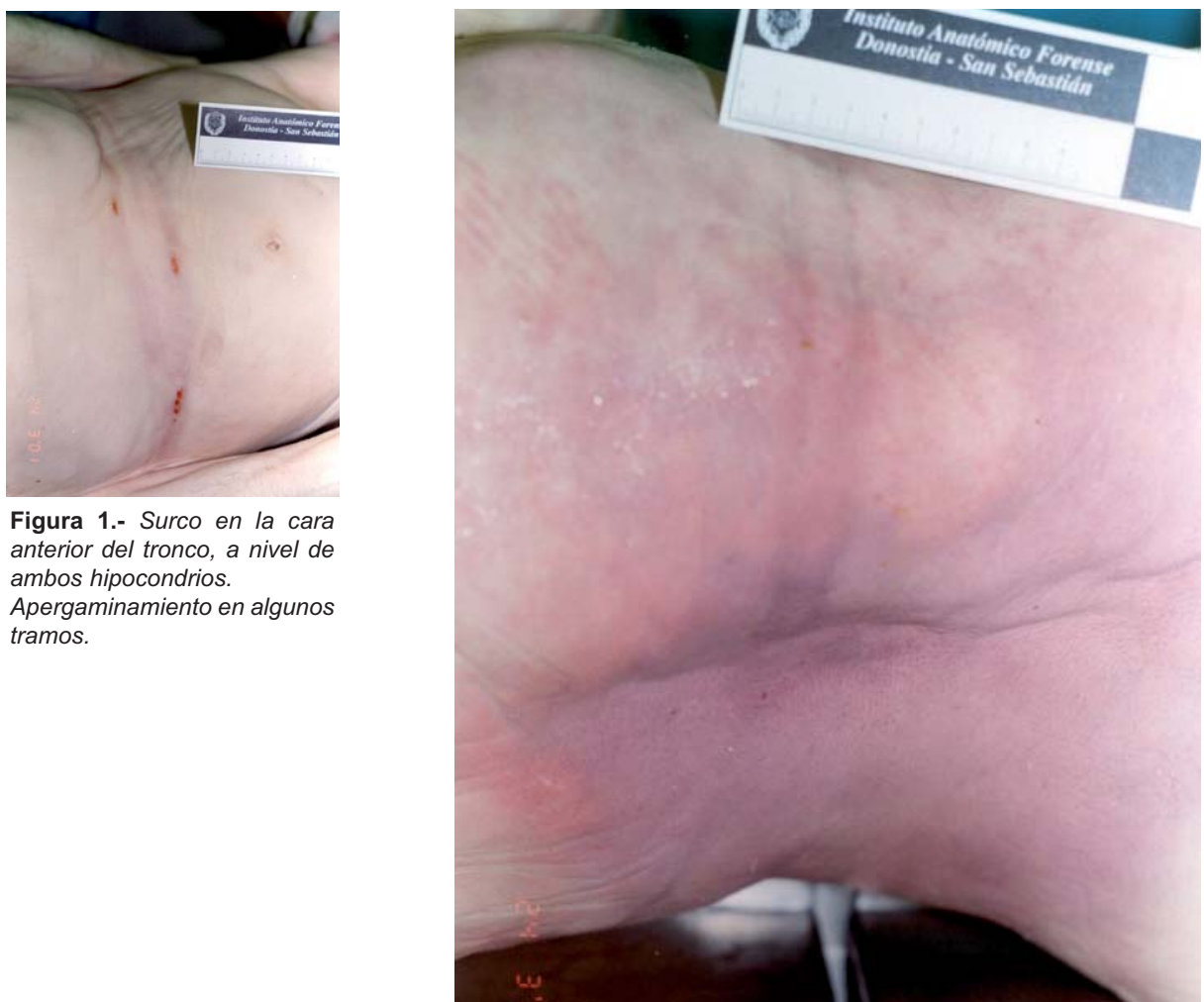

Figura 1.- Surco en la cara anterior del tronco, a nivel de ambos hipocondrios.

Apergaminamiento en algunos tramos.

Figura 2.- Surco en el plano dorsal, menos marcado que en el plano anterior.

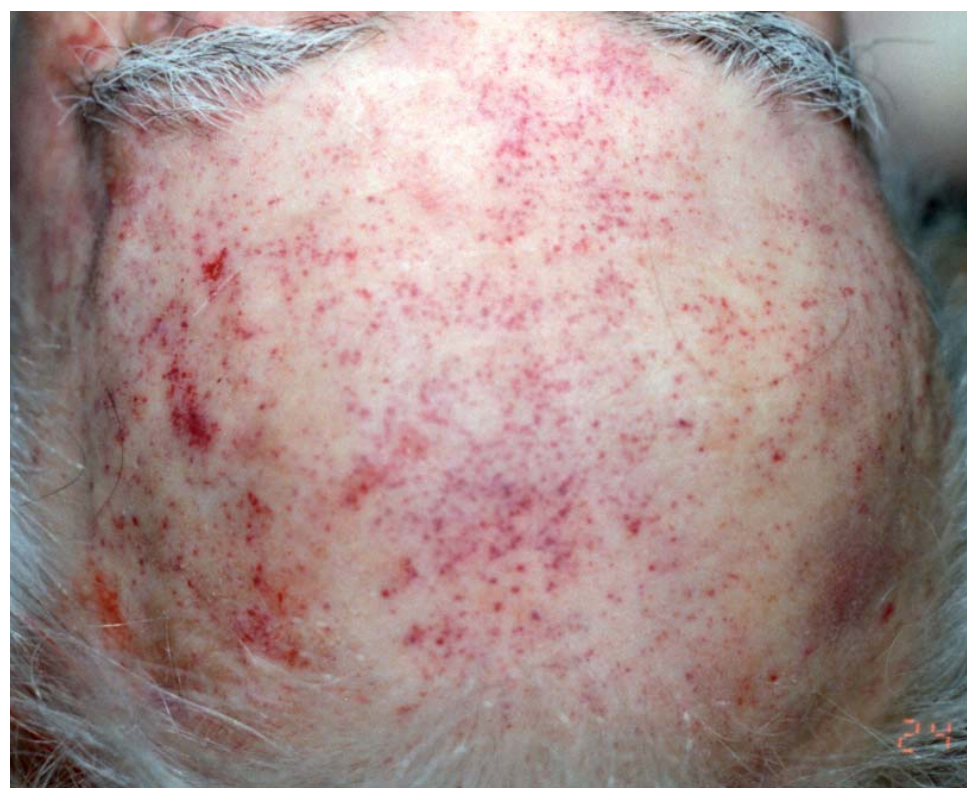

Figura 3.- Piqueteado equimótico. 


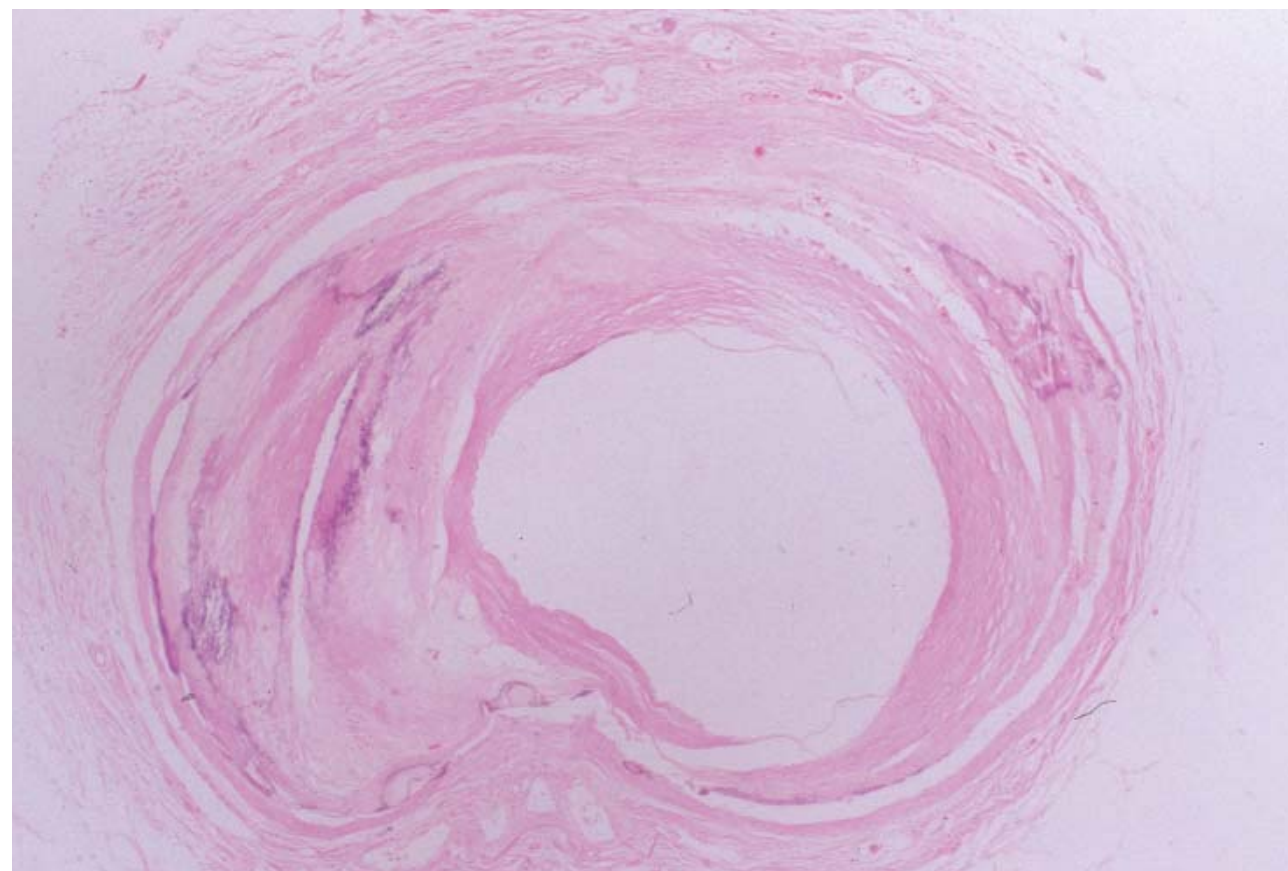

Figura 4.- Parénquima pulmonar: luz de un bronquiolo ocupada por material extraño particulado de origen alimenticio, parcialmente digerido y sin reacción leucocitaria asociada. H\&E.

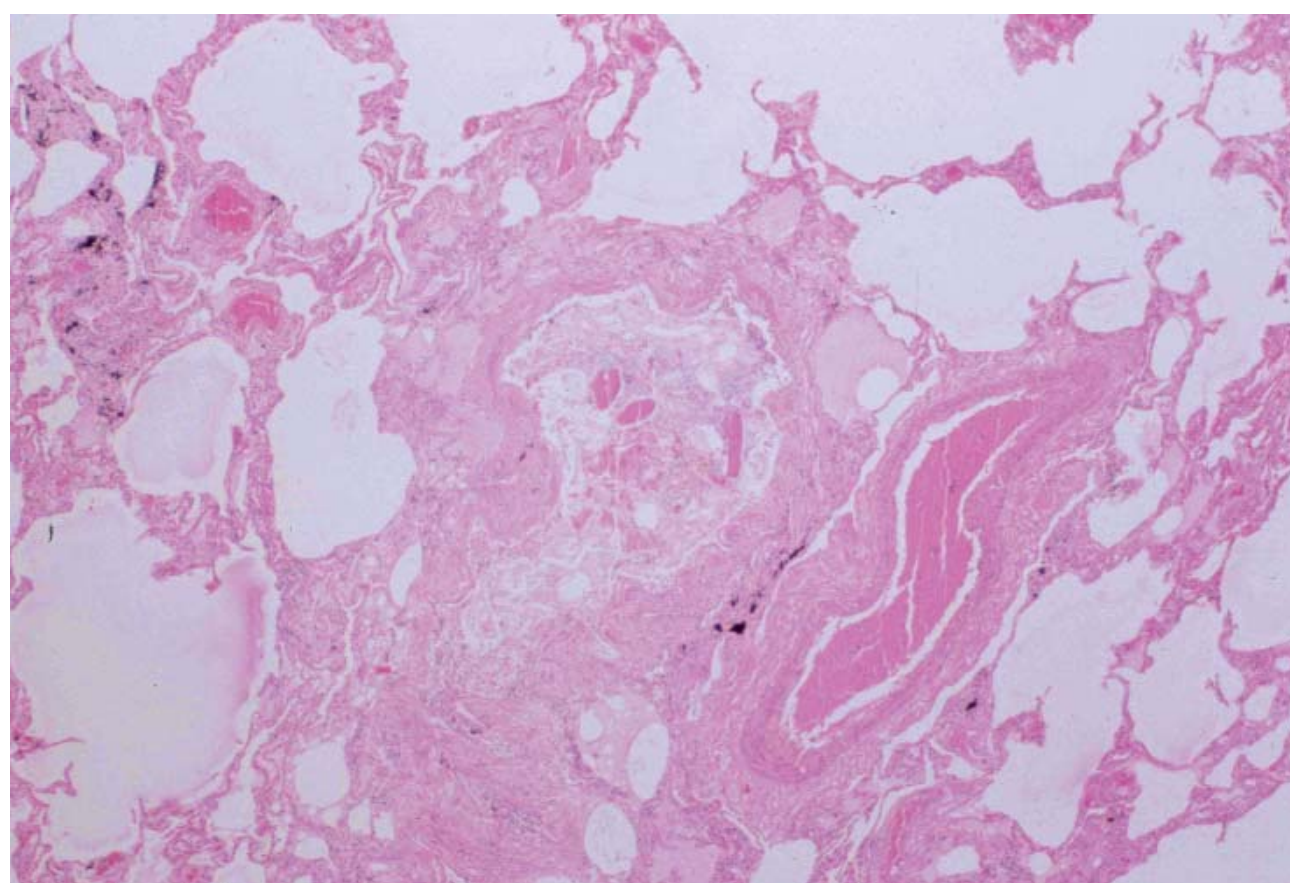

Figura 5.- Sección transversal de la arteria coronaria descendente anterior, con severa ateromatosis (depósitos concéntricos de lípidos complejos y calcificación) y estenosis de su luz. Tricrómico de Masson. 